\title{
Estimation of extreme wave height return periods from short-term interpolation of multi-mission satellite data: application to the South Atlantic
}

\author{
Julio Salcedo-Castro ${ }^{1}$, Natália Pillar da Silva ${ }^{2}$, Ricardo de Camargo ${ }^{2}$, Eduardo Marone ${ }^{3}$, and Héctor H. Sepúlveda ${ }^{4}$ \\ ${ }^{1}$ Centro de Estudios Avanzados, Universidad de Playa Ancha, Traslaviña 450, Viña del Mar, Chile \\ ${ }^{2}$ Departamento de Ciências Atmosféricas, Instituto de Astronomia, Geofísica e Ciências Atmosféricas, \\ Universidade de São Paulo, Rua do Matão, 1226, 05508-900, São Paulo, SP, Brazil \\ ${ }^{3}$ Centro de Estudos do Mar, Universidade Federal do Paraná, Av. Beira Mar s/n, 83255-000, Pontal do Sul, PR, Brazil \\ ${ }^{4}$ Departamento de Geofísica, Universidad de Concepción, Avenida Esteban Iturra s/n, Barrio Universitario, \\ Concepción, Chile
}

Correspondence: J. Salcedo-Castro (julio.salcedo@upla.cl)

Received: 16 October 2017 - Discussion started: 8 November 2017

Revised: 12 July 2018 - Accepted: 1 August 2018 - Published: 30 August 2018

\begin{abstract}
We analyzed the spatial pattern of wave extremes in the South Atlantic Ocean by using multiple altimeter platforms spanning the period 1993-2015. Unlike the traditional approach adopted by previous studies, consisting of computing the monthly mean, median or maximum values inside a bin of certain size, we tackled the problem with a different procedure in order to capture more information from short-term events. All satellite tracks occurring during a 2-day temporal window were gathered in the whole area and then gridded data were generated onto a mesh size of $2^{\circ} \times 2^{\circ}$ through optimal interpolation. The peaks over threshold (POT) method was applied, along with the generalized Pareto distribution (GPD). The results showed a spatial distribution comparable to previous studies and, additionally, this method allowed for capturing more information on shorter timescales without compromising spatial coverage. A comparison with buoy observations demonstrated that this approach improves the representativeness of short-term events in an extreme events analysis.
\end{abstract}

\section{Introduction}

In the context of climate change, the study of extreme waves has special relevance, as changes on regional and global wave patterns will impact coastal infrastructure, sediment trans- port and beach erosion, especially in low-elevation coastal areas (Mori et al., 2010; Hemer et al., 2012; Izaguirre et al., 2013). For instance, a 109-year numerical hindcast showed that the North Atlantic Ocean has experienced an increase in the yearly-mean significant wave height ( $\mathrm{SWH}$ ) north of $50^{\circ} \mathrm{N}$ (Bertin et al., 2013). These findings coincide with an increase in the global wind speed and SWH during the period 1985-2008, especially in the 90 and 99th percentiles (Young et al., 2011). Similar results were obtained by Chawla et al. (2013), who carried out a 31-year wave hindcast (19792009).

In spite of the advantages of reanalysis and modeling for studying the wave climate and extreme wave heights, these methods require validation. It has been shown that ERA40 reanalysis underestimates altimeter observations and has a larger uncertainty when comparing wave and wind data (Caires and Sterl, 2003). On the other hand, Chu et al. (2004) validated SWH modeled results in the South China Sea with observations from TOPEX/Poseidon (T/P) data. Similarly, Rocha et al. (2004) used altimeter data to validate a hindcast of the surface wave field in the South Atlantic Ocean. These authors mentioned that, given the limited local observational data, altimeter data represent an excellent source of information for the region. However, calibration and validation of this information, along with intercomparison, is necessary when dealing with single-mission or multi-mission altimetry data (Zieger et al., 2009). Consequently, direct observations 
from buoys and altimetry remain the most reliable sources to study wave climate.

The study of wave extremes by using altimeter data has proved to be very reliable and useful (Zieger et al., 2009; Vinoth and Young, 2011; Young et al., 2011, 2012). However, the most severe limitation of satellite altimeter data is the temporal and spatial sparseness (Hemer et al., 2010). This has been solved by averaging satellite track data from multiple missions within a certain quadrangle. Carter (1993) computed monthly mean values of SWH in $2^{\circ}$ latitude $\times 2^{\circ}$ longitude bins and compared them with buoy data. Challenor et al. (2004) adopted a method similar to that of Carter (1993), representing satellite tracks by their respective medians within a $2^{\circ}$ square. These authors used the 90th percentile to apply the peaks over threshold (POT) technique and the generalized Pareto distribution (GPD) to obtain a map of the 50 years of extreme wave height in the North Atlantic. Using a different approach, Chen et al. (2004) defined $1^{\circ}$ square bins and computed the return values of extreme waves that were represented on a global map through optimal interpolation. In a different way, Wimmer et al. (2006) defined $2^{\circ}$ squares to compute the median in each cell to obtain the return values. Vinoth and Young (2011) compared a few methods using different area sizes and representative statistics and concluded that, when using the POT method, a $2^{\circ}$ square is a good approach because under-prediction and under-sampling are avoided.

Some limitations are described for the methods above presented. One of the difficulties of using altimeter data is the inability to capture the response to atmospheric storms systems of relatively small dimension that move faster than satellite tracks (Cooper and Forristall, 1997). This involves a decision about the grid size. In this respect, Tournadre and Ezraty (1990) carried out a statistical analysis and concluded that a coverage of up to $200 \mathrm{~km}$ still represents data being part of the same processes. In a similar exercise, Panchang et al. (1999) arrived at the same conclusions about the usefulness of satellite track data within an area with a radius of $200 \mathrm{~km}$. According to Shanas et al. (2014) the balance between spatial and temporal resolution is partially accomplished by using a multiplatform altimeter data, obtaining a mesoscale variability of 100 to $300 \mathrm{~km}$. Other studies have shown that using the whole along-track data instead of statistics is more consistent with local observations when comparing by means of distribution functions (Cooper and Forristall, 1997).

In summary, the approaches adopted so far in previous studies (Carter, 1993; Alves and Young, 2003; Challenor et al., 2004; Chen et al., 2004; Caires and Sterl, 2005; Wimmer et al., 2006) consist of computing the monthly mean, median or maxima from different satellite along-track data and process this information in order to estimate the return period. In this study, we carried out an extreme wave analysis based on satellite altimeter data generated by a multi-satellite database that was already standardized, quality-controlled and corrected, from 1993 to 2015 (Queffeulou, 2004; Quef- feulou and Croizé-Fillon, 2017). The goal was to estimate the extreme value return based on data directly interpolated from along-track satellite data instead of using spatially averaged data. This method would provide a balance between spatial and temporal coverage so that more information associated with short timescale (and mesoscale) processes can be preserved without affecting the independence and representation of events like storms besides obtaining a good representation of ocean wave climate.

\section{Methods}

\subsection{Interpolation of along-track satellite data}

Satellite along-track altimeter data were obtained from the Laboratoire d'Océanographie Spatiale (LOS) and the Centre ERS d'Archivage et de Traitement (CERSAT), at the Institut Français de Recherche Exploitation de la mer (IFREMER) (France) (Queffeulou, 2004). As part of this project, altimeter measurements from seven to nine satellites are continuously quality-controlled, corrected and inter-calibrated to provide a homogeneous and consistent data set (Queffeulou, 2013; Queffeulou and Croizé-Fillon, 2017). The documentation for the global altimeter SWH data set describes a screening procedure to eliminate spurious measurements without affecting extreme wave records (Queffeulou and Croizé-fillon, 2010). The process consists of eliminating highest values obtained by the application of a $100 \mathrm{~km}$ running window along-track samples. Some criticism has arisen from some authors, arguing that this processing causes removal of extreme observations and therefore its application to analyze wave extremes is not reliable. However, a recent study by Hanafin et al. (2012) demonstrates that, after correction and processing, multi-mission altimeter data preserve extreme wave observations larger than $20 \mathrm{~m}$ during the passage of extratropical cyclones.

The study domain is delimited by 0 and $60^{\circ} \mathrm{S}$ latitude and $70^{\circ} \mathrm{W}$ to $25^{\circ} \mathrm{E}$ longitude, and the period was $1993-2015$. As a way to preserve more information from short-term events (5 days or less), we adopted a different approach. Instead of computing monthly averages or medians as representative values within individual quadrants of a gridded field, we firstly gathered all satellite tracks occurring during a 2-day temporal window in the whole area and then generated gridded data onto a mesh size of $2^{\circ} \times 2^{\circ}$ through optimal interpolation (objective mapping) (Fig. 1). Optimal interpolation is a standard and proven method consisting of a weighted linear combination of observations irregularly distributed (Wilkin et al., 2002; Melnichenko et al., 2014). Unlike smoothing methods, optimal interpolation is based on the data ensemble statistics, by applying the Gauss-Markov theorem. The objective is to assure a result where there is a minimum variance solution at each point. Therefore, provided there is a good coverage and knowledge of the data, this method yields 

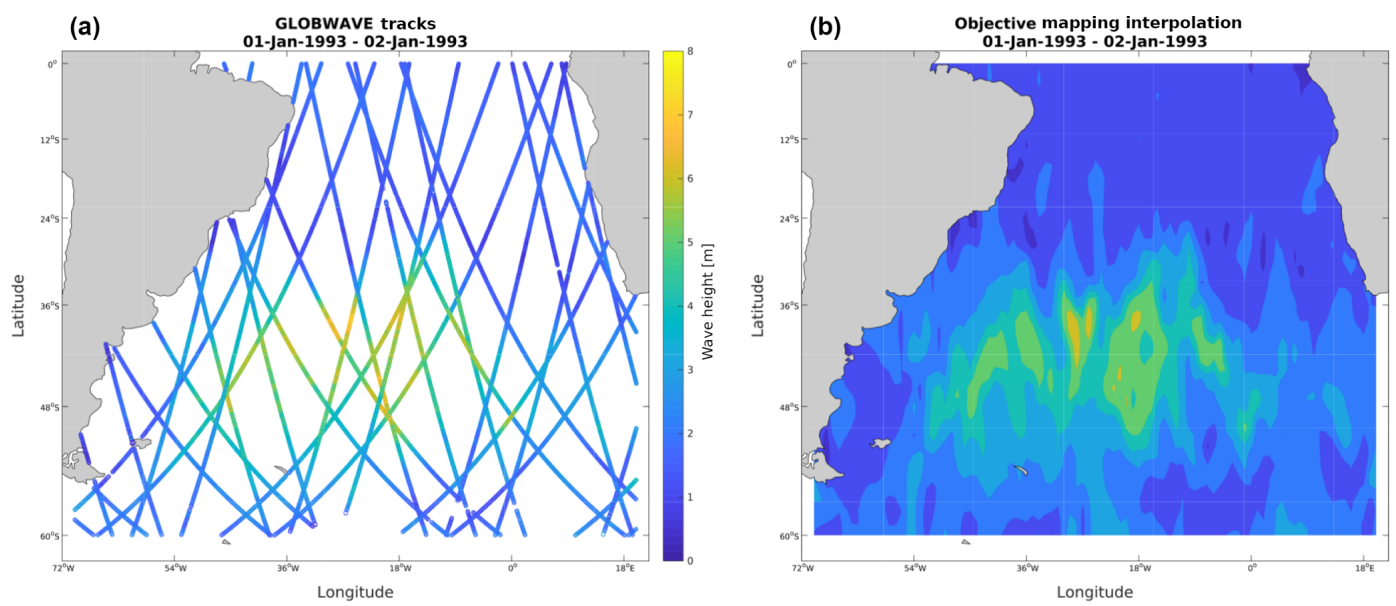

Figure 1. Example of multi-mission along-track data corresponding to a 2-day temporal window (a) and $2^{\circ} \times 2^{\circ}$ gridded SWH field interpolated through objective mapping (b).

quite accurate interpolated results (Bretherton et al., 1976). A detailed description of this method can be found in Daley (1991). The interpolation method was applied to grid scattered satellite tracks using a customized version of the OBJective MAPping interpolation (OBJMAP) package, developed by Kirill K. Pankratov, as part of a Mathworks@ MATLAB external toolbox named "Data Analysis and Modification" (datafun) provided by the Ocean Time Series Group at the Scripps Institution of Oceanography (Pankratov, 1995).

The mesh size of $2^{\circ} \times 2^{\circ}$ box was chosen because it was the most refined option to ensure that our 2-day averaged time series have no missing values in a $>20$ year range, from 1993 to 2015, and based on other authors (Cotton and Carter, 1994; Young, 1999; Woolf et al., 2002; Alves and Young, 2003; Hemer, 2010) and the results of Vinoth and Young (2011) about the acceptable tolerance of the peaks over threshold (POT) method to this grid resolution. A 2-day temporal window was shown to assure enough spatial coverage without compromising the temporal resolution and thus capturing most of the extreme events (short timescale) processes. This is a critical point as the main goal of this study is to try to capture as much information from extreme events as possible. A temporal window that is too long produces overlapping of many satellite tracks in a timescale where there is a mixing of different processes and, in some cases, some wave height extremes registered by some tracks can be masked by the following track. On the other hand, a temporal window that is too short does not provide enough tracks to generate an acceptable interpolation and gridding in the study area. Therefore, a minimum window of 2 days seems to assure a better representation of extreme events without compromising spatial representativeness. Moreover, this temporal window of $48 \mathrm{~h}$ allows for fulfilling the condition of statistical independence and aleatory distribution of the events for each grid point (Palutikof et al., 1999).
Four time series of buoy data were obtained from the Brazilian National Buoys Program (PNBOIA) to compare the interpolated results. The location of each buoy, corresponding to Recife (RE), Santos (SA), Florianópolis (FL) and Rio Grande (RG), along with its distance to the nearest grid point and temporal coverage are shown in Table 1.

To assess the goodness of the results, the statistical parameters used were the bias, correlation coefficient $(R)$, root mean square error (RMSE) and scattering index (SI), which were defined according to Shanas et al. (2014) as follows:

$$
\begin{aligned}
& \text { Bias }=\frac{1}{N} \sum_{l=1}^{N}\left(A_{i}-B_{i}\right), \\
& R=\frac{\sum_{l=1}^{N}\left[\left(A_{i}-\bar{A}\right)\left(B_{i}-\bar{B}\right)\right]}{\sqrt{\sum_{l=1}^{N}\left[\left(A_{i}-\bar{A}\right)^{2}\left(B_{i}-\bar{B}\right)^{2}\right]}}, \\
& \mathrm{RMSE}=\sqrt{\frac{1}{N} \sum_{l=1}^{N}\left(A_{i}-B_{i}\right)^{2},} \\
& \mathrm{SI}=\frac{\sqrt{\frac{1}{N} \sum_{l=1}^{N}\left[\left(A_{i}-\bar{A}\right)-\left(B_{i}-\bar{B}\right)\right]^{2}}}{\bar{B}} .
\end{aligned}
$$

The buoy time series were averaged every 2 days so as to obtain a representative value to compare with the single values obtained after interpolating the along-track altimeter data generated during the same period. Besides the statistical parameters described above, a quantile-quantile plot (Coles, 2001) was included to compare both series.

\subsection{Peaks over threshold method}

The application of the POT technique implies choosing a threshold value $(u)$ over which the exceedances will be obtained. Therefore, this step is critical to adjust the exceedances to a GPD and needs to be carried out carefully. The 
Table 1. Buoys belonging to the Brazilian National Buoys Program (PNBOIA) used to compare the interpolated series from LOS.

\begin{tabular}{lrrrr}
\hline Buoy location & Latitude & Longitude & $\begin{array}{r}\text { Distance to nearest } \\
\text { grid point }(\mathrm{km})\end{array}$ & Temporal coverage \\
\hline Recife (RE) & $34.58^{\circ} \mathrm{S}$ & $7.29^{\circ} \mathrm{W}$ & 102 & July 2012-March 2014 \\
Santos (SA) & $44.93^{\circ} \mathrm{S}$ & $25.27^{\circ} \mathrm{W}$ & 131 & January 2012-April 2014 \\
Florianópolis (FL) & $47.39^{\circ} \mathrm{S}$ & $28.52^{\circ} \mathrm{W}$ & 89 & February 2011-February 2013 \\
Rio Grande (RG) & $49.88^{\circ} \mathrm{S}$ & $31.58^{\circ} \mathrm{W}$ & 48 & April 2009-January 2013 \\
\hline
\end{tabular}

choice of the threshold value was tested by using the mean excess plot (MEP) method (Ghosh and Resnick, 2010). This method evaluates how well the chosen threshold fits within an expected distribution of thresholds mean and these values are represented in the MEP as an approximately linear segment (Coles, 2001). We tested threshold values of $93 \%$, $95 \%$ and $97 \%$ for all buoy time series.

The chosen method to estimate return values was the generalized Pareto distribution (GPD). The GPD has the following expression (Belitsky and Moreira, 2007):

$G_{\xi, \beta}(y)= \begin{cases}1-\left(1+\xi \frac{y}{\beta}\right)^{-\frac{1}{\xi}}, & \xi \neq 0, \\ \left(1-e^{-\frac{y}{\beta}}\right), & \xi=0,\end{cases}$

where $y$ represents the exceedances with respect to a threshold value $u$. Here, $\beta$ is a shape parameter and $\xi$ is a scale parameter. In this distribution, $y \geq 0$ for $\xi \geq 0$. The parameters $\beta$ and $\xi$ can be estimated by different methods, like the maximum likelihood method (ML), method of moments (MOM), Pickand's estimator (PKD) and the probability weighted moments (PWM). From these methods, MOM and PWM exhibit better fit quality (Campos, 2009). Consequently, we adopted PWM to estimate the parameters of the GPD, as also recommended by Caires (2011). A Kolmogorov-Smirnov test was applied to test that each individual series of exceedances belongs to a GPD with the same parameters, with a $95 \%$ of significance. A two sample Kolmogorov-Smirnov test is a non-parametric hypothesis test that compares the sample's cumulative distribution functions and evaluates differences between each sample, indicating that those samples belong to similar distributions. In our study, random empirical time series were created using GPD shape and scale parameters for each grid point series and then compared with the excesses above threshold series.

To determine the extreme value for a certain return period by fitting the GPD, we used the following expression (Campos, 2009):

$x_{\mathrm{r}}=u+\frac{\beta}{\xi}\left[\left(\frac{n}{N_{\mathrm{u}}}(1-p)\right)^{-\xi}-1\right]$,

where $N_{\mathrm{u}}$ is the total number of exceedances above the threshold, $x_{\mathrm{r}}$ is the extreme to be computed, $n$ is the total number of observations in the series and $p$ is the probability of not exceeding. The probability of not exceeding is given by

$p=1-\frac{1}{N_{\mathrm{e}}}$

where $N_{\mathrm{e}}$ is the total number of expected exceedances for a given return period $p_{\mathrm{r}}$, obtained form the expression

$N_{\mathrm{e}}=p_{\mathrm{r}} \frac{N_{\mathrm{u}}}{N_{\text {years }}}$,

where $N_{\text {years }}$ is the number of years considered in the analysis. In this case, we computed the extreme value for a return period $p_{\mathrm{r}}=10, p_{\mathrm{r}}=25$ and $p_{\mathrm{r}}=50$.

The analytic procedures and computation of return values were performed with the MATLAB Wave Analysis for Fatigue and Oceanography (WAFO) tool (Brodtkorb et al., 2000).

\section{Results and discussion}

A useful approach to evaluate the threshold choice for a POT analysis can be performed by the analysis of the MEP. Figure 2 shows the MEP for the GLOBWAVE data, both raw and optimally interpolated, calculated for the nearest point to the buoy data. There are differences between the raw and interpolated data (gray areas), but for all cases, all three tested values $(93 \%, 95 \%$ and $97 \%)$ could be used as threshold value for the estimation of return period as they are located in a region with almost linear MEP (Fig. 2). Consequently, following Caires and Sterl (2005) and Challenor et al. (2004), we used the 97th percentile as threshold value, which was set as spatially variable (Alves and Young, 2003).

A reasonable agreement $(R \geq 0.64)$ is observed between the interpolated LOS data and the buoy series (Fig. 3), considering that the comparison is between 2-day alongtrack altimeter data and 2-day average buoy data. An increase from north to south in the magnitude of the bias and RMSE can be observed (Fig. 4). A similar trend in the average SWH is observed from north to south, where Recife shows an average $\mathrm{SWH}$ of $1.5 \mathrm{~m}$ (90th percentile: $1.9 \mathrm{~m}$ ); Santos, $1.9 \mathrm{~m}$ (90th percentile: $2.7 \mathrm{~m}$ ); Florianópolis, $2.1 \mathrm{~m}$ (90th percentile: $2.9 \mathrm{~m}$ ), and Rio Grande, $2.3 \mathrm{~m}$ (90th per- 

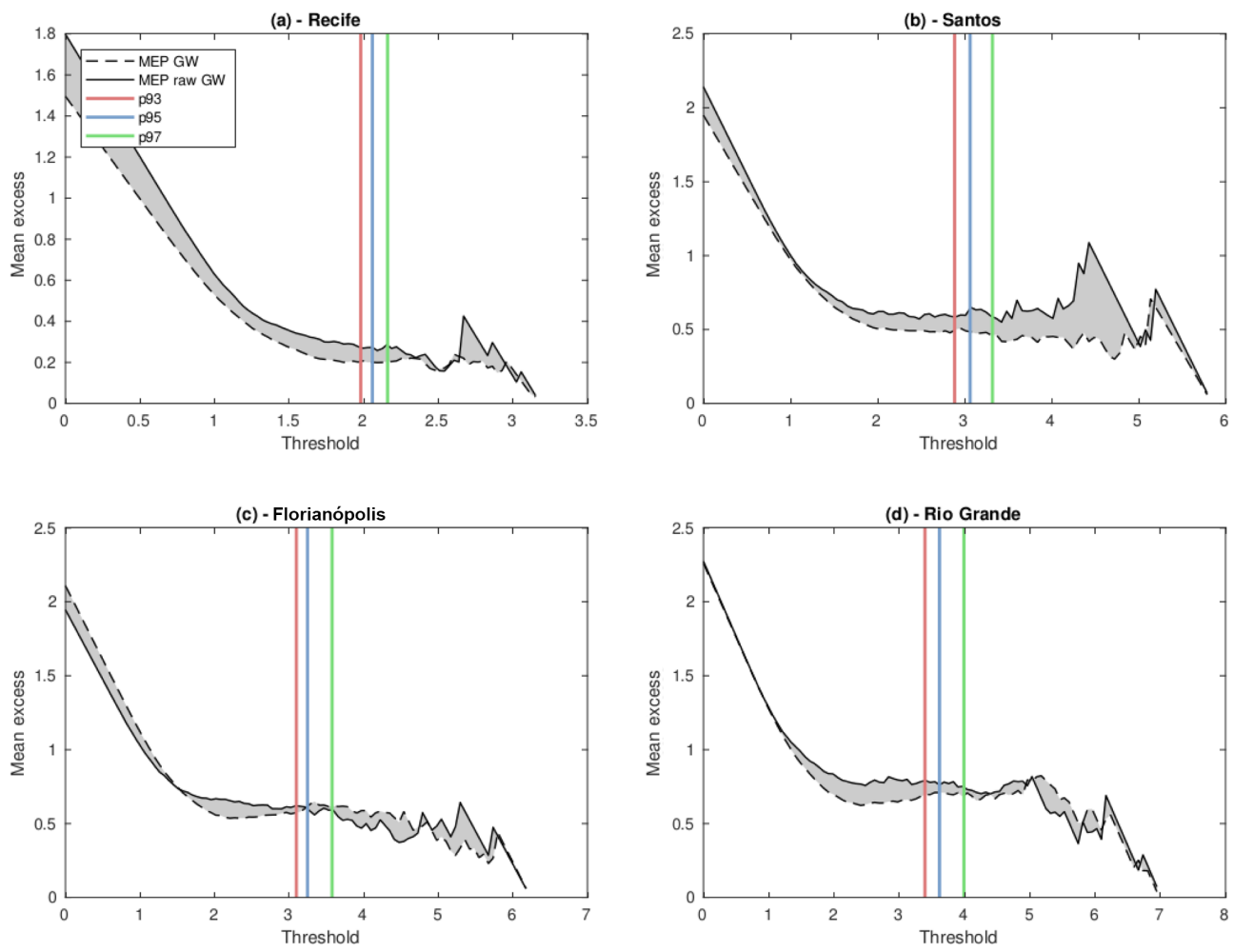

Figure 2. Comparison of mean excess plot (MEP) for Recife, Santos, Florianópolis and Rio Grande. The thresholds correspondent to $93 \%$, $95 \%$ and $97 \%$ (red, blue and green vertical lines, respectively) are shown.

centile: $3.2 \mathrm{~m}$ ). All these features and trends are well captured by the interpolated LOS series. Recife station shows a more regular wave climate caused by the uniform westward winds of the equatorial latitude, which is in contrast to the other stations more exposed to extreme waves associated with the passage of cyclonic events and ocean swell from the south (Fig. 3). Rio Grande is the closest station to the coast $(48 \mathrm{~km})$ and there may be some corruption of the altimeter data by irregularities in the coastline that can be responsible for this discrepancy.

In order to test the similitude between the optimally interpolated data with buoy measurements, the period from March to June of 2012 was selected, based on buoy data availability. These tracks (Fig. 5) were provided by the Group of Climate Studies of IAG/USP and were obtained with the methodology proposed by Murray and Simmonds (1991), applied to NCEP reanalysis fields (Kalnay et al., 1996). The time series for the southernmost locations, Santos, Florianópolis and Rio Grande, are shown in Fig. 5b, where the passage of the selected cyclones is depicted. Rising values of SWH in all locations for cyclone cases A, B and I can be observed, which can be described as typical extratropical events affecting the whole southern coast of Brazil. Cyclones D, G and $\mathrm{J}$ can be characterized as subtropical cases that mainly affect the northernmost location (Santos) in terms of SWH. Intermediate situations like cyclones $\mathrm{E}$ and $\mathrm{F}$ appeared affecting only Rio Grande and Florianópolis. All these events showed better correspondence between buoy and optimally interpolated data at Santos station. Florianópolis presented a fluctuating behavior, whereas Rio Grande showed mostly a slight overestimation of optimally interpolated values. Therefore, in general, the short-term variability is well captured by the optimally interpolated data, even with different behavior between the buoy locations.

Results of thresholds obtained after interpolation are shown in Fig. 6, along with results from ERA-Interim computed for the same period, in order to compare this approach with those results from gridded reanalysis products. Both distributions are similar and show the same general pattern, although data from LOS provide a more detailed description. However, these details should be treated with caution because additional analysis are necessary to demonstrate that optimal interpolation resolves more real structures in the data. Higher threshold values are observed south of $35^{\circ}$, exhibiting maximum values in the southeastern Atlantic, with values $>5 \mathrm{~m}$. Similarly, Hemer et al. (2010) obtained 

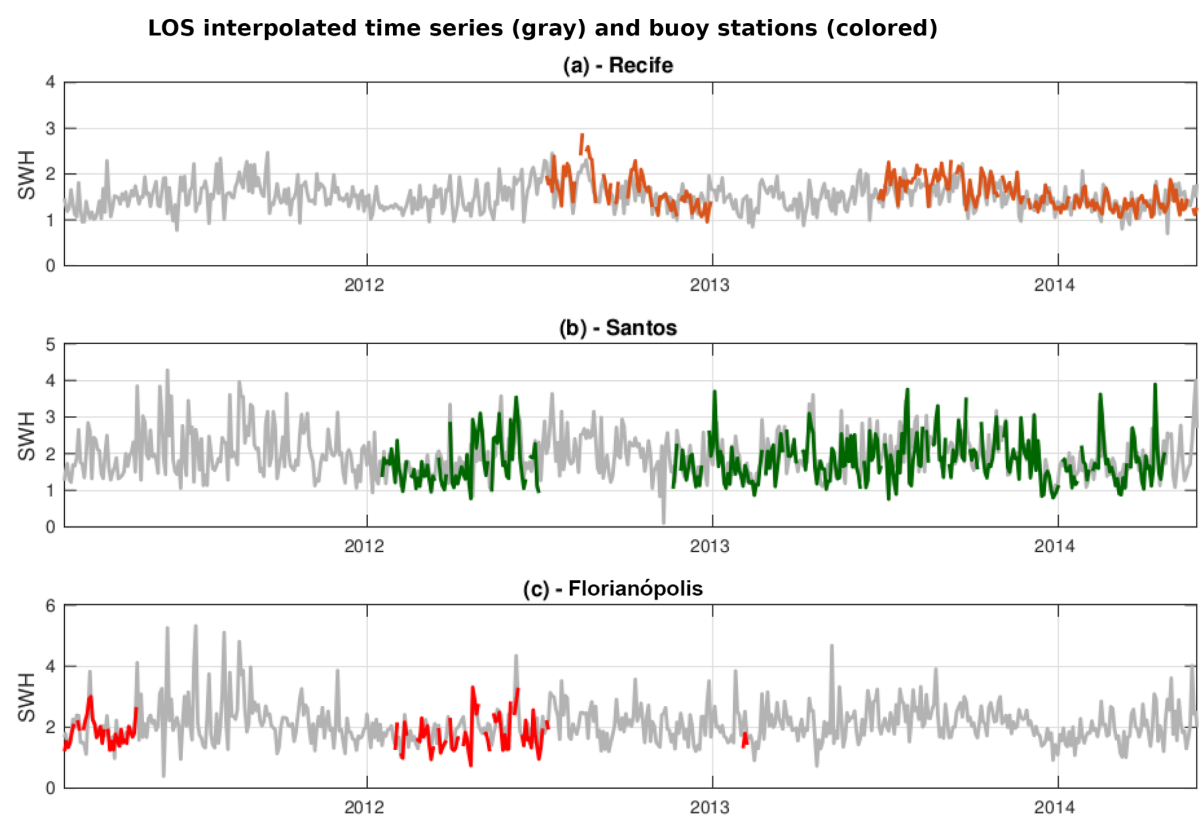

(d) - Rio Grande

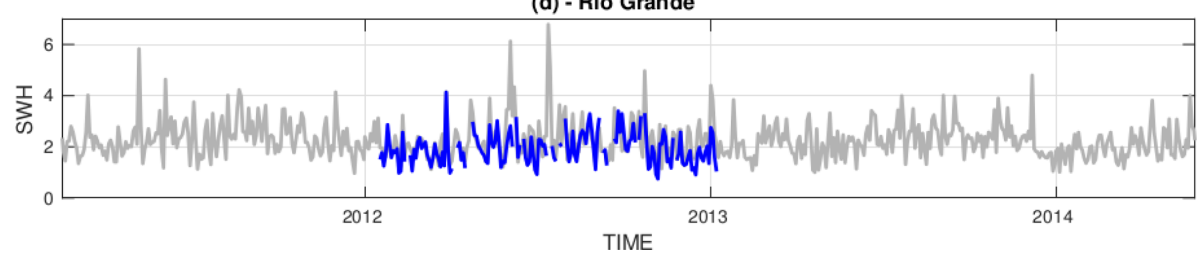

Figure 3. Time series for the LOS interpolated data (gray) in points near buoy stations in Recife (orange, a), Santos (green, b), Florianópolis (red, c) and Rio Grande (blue, d).

monthly SWH climatology in the Southern Hemisphere and observed a strong latitudinal gradient, with largest wave heights toward the Indian Ocean. This is in agreement with the extreme values obtained in our study, where the highest wave height thresholds are shown near South Africa. Our results are consistent with those described by other authors, like Mori et al. (2010), with SWH $<2 \mathrm{~m}$ at the Equator and SWH $>6 \mathrm{~m}$ in the southwest region of the South Atlantic. The observed zonal variation in the extreme wave height agrees with that observed by Alves and Young (2003). In this sense, Alves and Young (2003) described three zonal bands: a higher latitude region, characterized by higher SWH; an equatorial band, with lower SWH and a transitional zone, between 20 and $40^{\circ} \mathrm{S}$. In this respect, Young et al. (2012) states that the higher SWH found in the subtropical region of the South Atlantic is associated with swell generated by storms in the Southern Ocean.

The 10-, 25- and 50-year return values are shown in Figs. 7, 8 and 9, respectively, including a comparison with results from the ERA-Interim. Our results are similar to those found by Young et al. (2012) and there is a close similitude to the zonal pattern and large extremes between 45 and $60^{\circ}$ in the Southern Ocean (Chen et al., 2004). However, our results showed a more detailed map, with distribution of return val- ues 1-2 $\mathrm{m}$ lower (see Fig. 6a, b in Chen et al., 2004). This difference can arise because Chen et al. (2004) used only one (TOPEX) altimeter data set collected during a period of 8 years. This contrast has been highlighted by Shanas et al. (2014), who demonstrated that multi-mission products have advantages in estimating extreme waves when compared with single-mission along-track data. Qualitatively, these results are similar to those obtained by Izaguirre et al. (2011), although these authors used monthly maximum SWH values. The extreme wave height distribution also resembles the description given by Jiang and Chen (2013), where a northeastward swell propagation from the Drake Passage can be distinguished in the subtropical area of the South Atlantic Ocean. In contrast, ERA-Interim produces higher return values for all three periods analyzed. Our results agree with maximum return values around $13 \mathrm{~m}$, whereas ERAInterim overestimates this range, exhibiting maximum values of $>18 \mathrm{~m}$, especially in the southeastern part of the domain. Other studies have demonstrated this ERA-Interim overestimation (Kumar and Naseef, 2015), as well as under- and overestimation (Shanas and Sanil Kumar, 2014; Samayam et al., 2017), depending on local conditions and local processes. However, the main cause of this discrepancy seems to be the irregular distribution of tracks points in the do- 

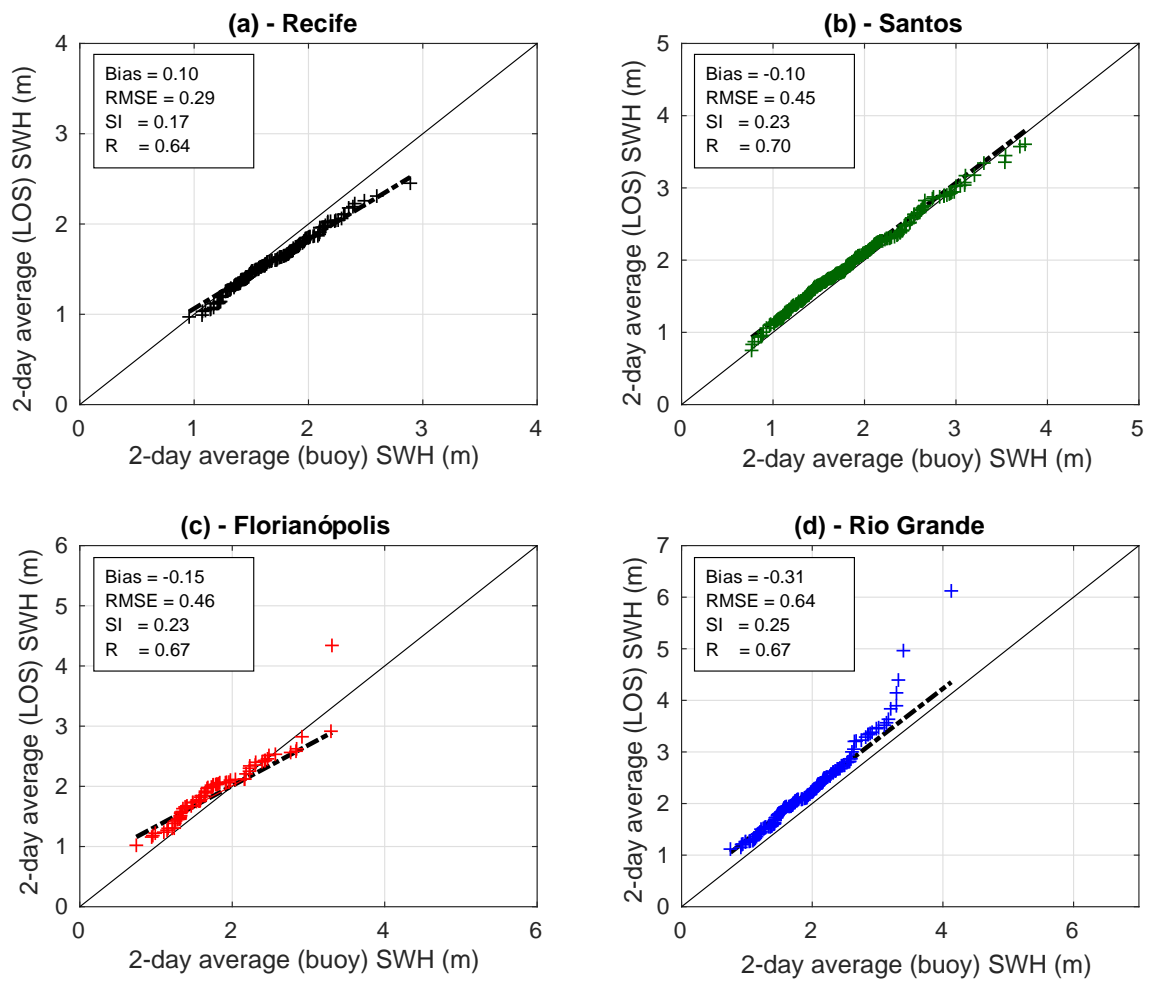

Figure 4. Comparison of quantile-quantile plots between 2-day averaged buoy data for stations in Recife (a), Santos (b), Florianópolis (c), Rio Grande (d) and the nearest LOS interpolated time series.

main, where, as a consequence, the southeastern part has a lower spatiotemporal density of track points. When plotting the mean difference between ERA-Interim and LOS return values (not shown here), it is possible to confirm that larger differences are associated with less data available in the region between $40^{\circ}$ and the southern boundary of the domain. This missing information causes an underestimation in that area but, in general, this method works well when data are available.

The more detailed pattern obtained in this study may be related to the higher temporal resolution that captures the passage of tropical and extratropical cyclones, in contrast to the results obtained by Caires and Sterl (2005). Another difference was given by the threshold of 97 th percentile used in our study versus the 90th percentile used by Caires and Sterl (2005) and others. The better suitability of the 97th percentile would be related to the treatment of the along-track data, which was not averaged in this study. On the other hand, the spatial variability in the return values resembles the description given by Caires and Sterl (2005), who assert that a long data set and a chosen fixed threshold would assure a fair representation of major spatial features.

The chosen grid size produced results comparable to those obtained by other authors (Cotton and Carter, 1994; Young, 1999; Panchang et al., 1999; Woolf et al., 2002; Alves and Young, 2003; Vinoth and Young, 2011), confirming that a mesh element size of $2^{\circ} \times 2^{\circ}$ is an acceptable choice. Furthermore, this size proved to be suitable to apply the POT method, which is sensitive to undersampling and threshold value, as compared to more robust methods like the initial distribution method (IDM; Alves and Young, 2003; Vinoth and Young, 2011; Young et al., 2012). However, as stated by Vinoth and Young (2011) and Young et al. (2012), the availability of long time series allows for acceptable results with the POT method. The application of POT and GPD to estimate extreme wave return values, consequently, is suitable to undertake in this study, as also proven by previous work (Challenor et al., 2004; Wimmer et al., 2006).

An important point to consider is the coastal location of the buoys and the distance between the grid point and the coastal buoy, as Shanas et al. (2014) mentioned in their comparison. These factors affect the results as buoys close to the coast are under complex interaction between the topography, waves and wind. On the other hand, satellite signals get contaminated due to the closeness to the continent and radiometer footprints. 

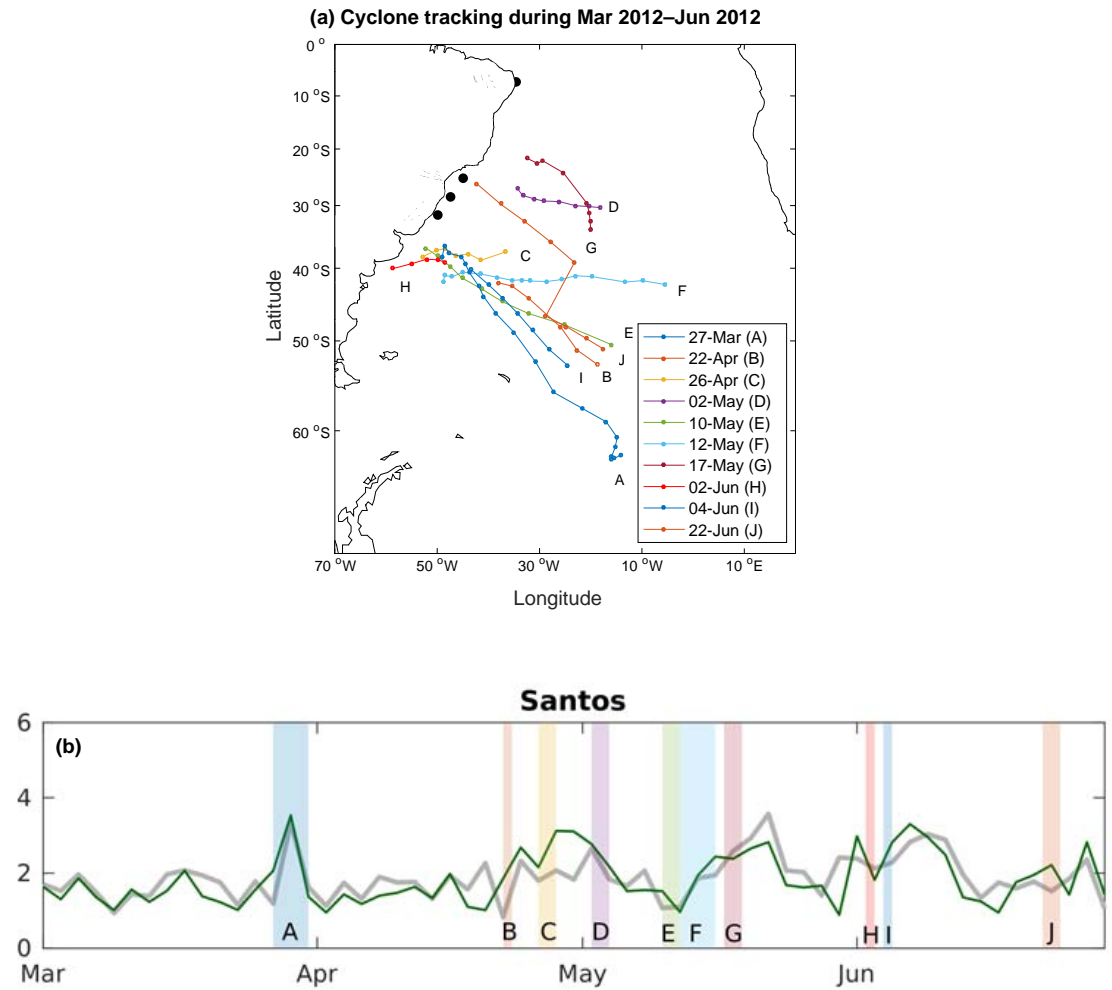

Florianópolis

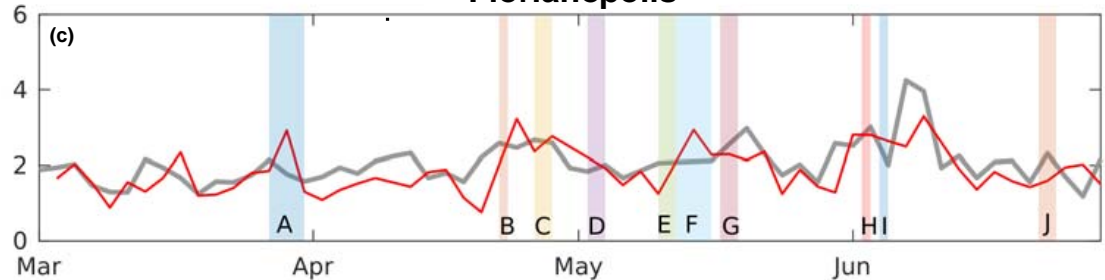

Rio Grande

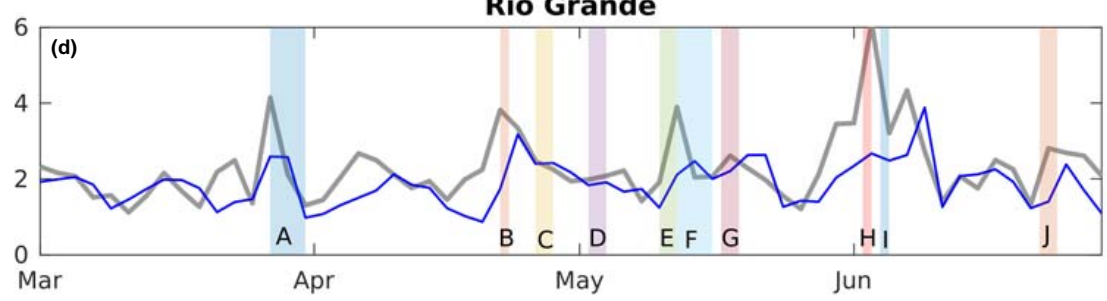

Figure 5. (a) Extratropical cyclone tracking in the South Atlantic Ocean between March and June 2012. Buoy stations are marked in black. Initial dates for cyclone occurrences are indicated and each case has a letter assigned (A-J). (b-d) Time series from linearly interpolated buoy stations (gray) and the nearest correspondent gridded LOS for Santos (green, b), Florianópolis (red, c) and Rio Grande (blue, d). Extratropical cyclone occurrences shown in (a) are marked with letters A-J.

\section{Conclusions}

A new methodological approach was proposed in this study. The multi-mission tracks were gathered in 2-day temporal windows and then gridded by means of optimal interpolation before applying the peaks over threshold (POT) method along with the generalized Pareto distribution (GPD). Comparison of gridded data with coastal buoy series showed a good agreement, where most of the short-timescale variability associated with the passage of cyclones could be captured. Consequently, the mapping of extreme wave height return periods showed a good agreement with previous studies and provided more detailed features due to the multi-mission nature of the data and the short-term temporal window. A further improvement of this method should focus on seasonal and monthly periods, as well as the response of local wave 

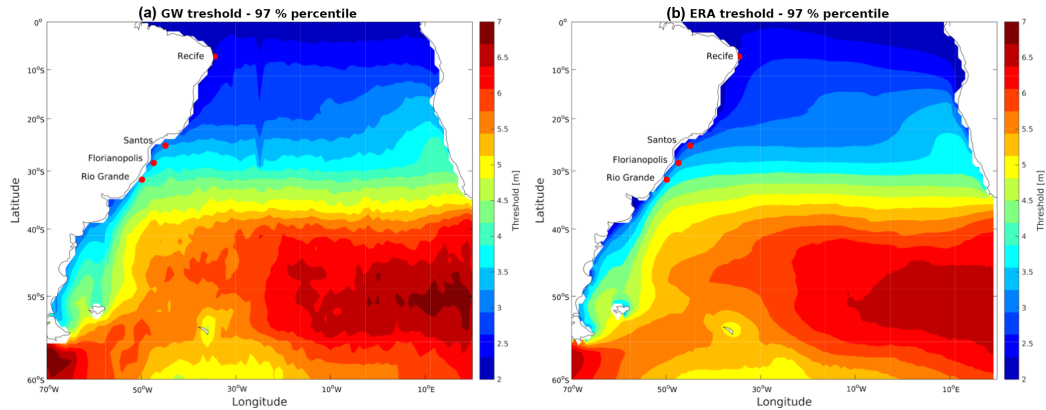

Figure 6. Spatial pattern of SWH threshold $(97 \%)$ values from interpolated LOS data (a) and from ERA-Interim (b) in the South Atlantic.
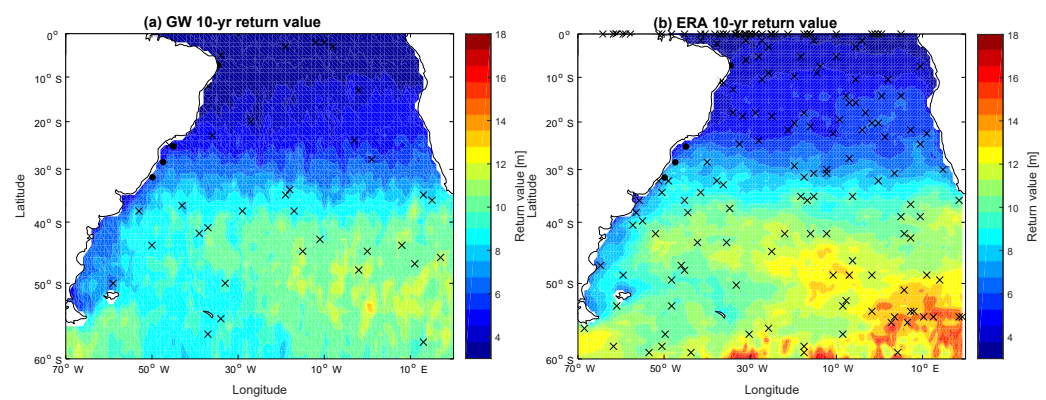

Figure 7. Distribution of 10-year return values from interpolated LOS data (a) and from ERA-Interim (b) in the South Atlantic. Crosses represent the series that did not pass the Kolmogorov-Smirnov test.
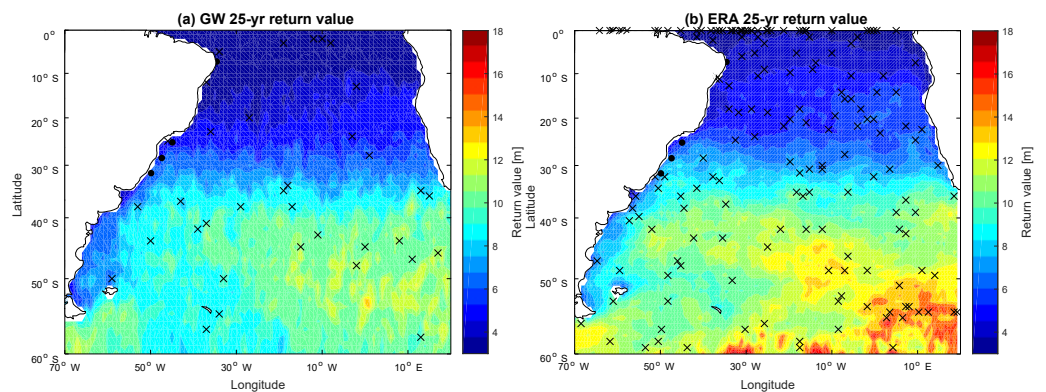

Figure 8. Distribution of 25-year return values from interpolated LOS data (a) and from ERA-Interim (b) in the South Atlantic. Crosses represent the series that did not pass the Kolmogorov-Smirnov test.
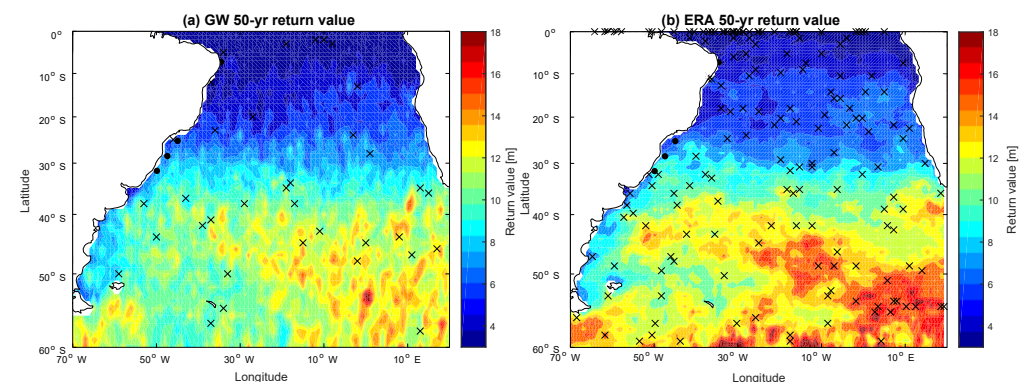

Figure 9. Distribution of 50-year return values from interpolated LOS data (a) and from ERA-Interim (b) in the South Atlantic. Crosses represent the series that did not pass the Kolmogorov-Smirnov test. 
climate to the passage of tropical and extratropical cyclones. In this sense, a local and regional focus is justified, as the change in the wave climate would not be globally uniform but the mean and maximum wave heights would increase in middle latitudes and in Antarctica, along with an increase in the maximum wave heights associated with tropical cyclones (Mori et al., 2009, 2010).

Data availability. Altimeter wave data are made available by Ifremer (ftp://ftp.ifremer.fr/ifremer/cersat/products/swath/altimeters/ waves/) (Ifremer-CERSAT, 2016).

Author contributions. NdS carried out POT computation and data processing, $\mathrm{RdC}$ contributed to the analytical discussion and data analysis, EM contributed to the discussion and editing of the manuscript and HS collected and processed along-track satellite data. JSC prepared the manuscript with contributions from all coauthors. All co-authors reviewed and discussed the final version of the manuscript.

Competing interests. The authors declare that they have no conflict of interest.

Acknowledgements. This research is funded by Lloyd's Register Foundation, which helps to protect life and property by supporting engineering-related education, public engagement and the application of research. We thank the Group of Climate Studies of IAG/USP for providing cyclone track information. H. H. Sepúlveda was supported by a University of Concepción fellowship.

Edited by: Andreas Sterl

Reviewed by: Andreas Sterl and two anonymous referees

\section{References}

Alves, J.-H. G. and Young, I. R.: On estimating extreme wave heights using combined Geosat, Topex/Poseidon and ERS-1 altimeter data, Appl. Ocean Res., 25, 167-186, https://doi.org/10.1016/j.apor.2004.01.002, 2003.

Belitsky, V. and Moreira, F. M.: Emprego do método do "PeaksOver-Threshold" na estimação de risco; uma exposição abragente, detalhada mas simples, in: Third Brazilian Conference on Statistical Modelling in Insurance and Finance, p. 107, Maresias, São Paulo, Brasil, 2007.

Bertin, X., Prouteau, E., and Letetrel, C.: A significant increase in wave height in the North Atlantic Ocean over the 20th century, Glob. Planet. Change, 106, 77-83, https://doi.org/10.1016/j.gloplacha.2013.03.009, 2013.

Bretherton, F. P., Davis, R. E., and Fandry, C. B.: A technique for objective analysis and design of oceanographic experiments applied to MODE-73*, Deep-Sea Res., 23, 559-582, 1976.

Brodtkorb, P. A., Johannesson, P., Lindgren, G., Rychlik, I., Ryden, J., and Sjo, E.: WAFO - a Matlab toolbox for analysis of random waves and loads, in: The Proceedings of The Tenth International Offshore and Polar Engineering Conference, 3., 343-350, International Society of Offshore and Polar Engineers, Seattle, 2000.

Caires, S.: Extreme value analysis: Wave data, JCOMM Technical Report No. 57, Tech. Rep. 57, Joint Technical Commission for Oceanography and Marine Meteorology, 2011.

Caires, S. and Sterl, A.: Validation of ocean wind and wave data using triple collocation, J. Geophys. Res., 108, 3098, https://doi.org/10.1029/2002JC001491, 2003.

Caires, S. and Sterl, A.: 100-Year Return Value Estimates for Ocean Wind Speed and Significant Wave Height from the ERA-40 Data, J. Climate, 18, 1032-1048, 2005.

Campos, R. M.: Análise dos extremos de onda no Rio de Janeiro associados a ciclones estratropicais no Atlântico Sul, Master's thesis, Universidade Federal do Rio de Janeiro, 2009.

Carter, D. J. T.: Estimating extreme wave heights in the NE Atlantic from GEOSAT data, Tech. Rep., Institute of Oceanographic Sciences Deacon Laboratory, London, 1993.

Challenor, P. G., Wimmer, W., and Ashton, I.: Climate change and extreme wave heights in the North Atlantic, in: Envisat and ERS Symposium, -572, European Space Agency, Salzburg, Austria, 2004.

Challenor, P. G., Wimmer, W., and Ashton, I.: Climate change and extreme wave heights in the North Atlantic, European Space Agency, (Special Publication) ESA SP, 572, 1253-1257, 2005.

Chawla, A., Spindler, D. M., and Tolman, H. L.: Validation of a thirty year wave hindcast using the Climate Forecast System Reanalysis winds, Ocean Modell., 70, 189-206, https://doi.org/10.1016/j.ocemod.2012.07.005, 2013.

Chen, G., Bi, S.-W., and Ezraty, R.: Global structure of extreme wind and wave climate derived from TOPEX altimeter data, Int. J. Remote Sens., 25, 1005-1018, https://doi.org/10.1080/01431160310001598980, 2004.

Chu, P. C., Qi, Y., Yuchun, C., Shi, P., and Mao, Q.: South China Sea Wind-Wave Characteristics, Part I: Validation of Wavewatch-III Using TOPEX/Poseidon Data, J. Atmos. Ocean. Tech., 21, 17181734, 2004.

Coles, S. G.: An introduction to Statistical Modeling of Extreme Values, Springer-Verlag, London, https://doi.org/10.1007/978-14471-3675-0, 2001.

Cooper, C. K. and Forristall, G. Z.: The Use of Satellite Altimeter Data to Estimate the Extreme Wave Climate, J. Atmos. Ocean. Tech., 14, 254-266, 1997.

Cotton, P. D. and Carter, D. J. T.: Cross calibration of TOPEX, ERS-I, and Geosat wave heights, J. Geophys. Res., 99, 25025, https://doi.org/10.1029/94JC02131, 1994.

Daley, R.: Atmospheric data analysis, Cambridge, New York, Cambridge University Press, includes bibliographical references, 439-454, and index, 1991.

Ghosh, S. and Resnick, S.: A discussion on mean excess plots, Stochastic Processes and their Applications, 120, 1492-1517, https://doi.org/10.1016/j.spa.2010.04.002, 2010.

Hanafin, J. A., Quilfen, Y., Ardhuin, F., Sienkiewicz, J., Queffeulou, P., Obrebski, M., Chapron, B., Reul, N., Collard, F., Corman, D., De Azevedo, E. B., Vandemark, D., and Stutzmann, E.: Phenomenal sea states and swell from a north atlantic storm in february 2011: A comprehensive analysis, B. Am. Meteor. Soc., 93, 18251832, https://doi.org/10.1175/BAMS-D-11-00128.1, 2012. 
Hemer, M. A.: Historical trends in Southern Ocean storminess: Long-term variability of extreme wave heights at Cape Sorell, Tasmania, Geophys. Res. Lett., 37, L18601, https://doi.org/10.1029/2010GL044595, 2010.

Hemer, M. A., Church, J. A., and Hunter, J. R.: Variability and trends in the directional wave climate of the Southern Hemisphere, Int. J. Climatol., 30, 475-491, https://doi.org/10.1002/joc.1900, 2010.

Hemer, M. a., Wang, X. L., Weisse, R., and Swail, V. R.: Advancing Wind-Waves Climate Science, B. Am. Meteor. Soc., 93, 791796, https://doi.org/10.1175/BAMS-D-11-00184.1, 2012.

Ifremer-CERSAT: GlobWave Project, available at: ftp://ftp.ifremer. $\mathrm{fr} /$ ifremer/cersat/products/swath/altimeters/waves/ (last access: June 2015), 2016.

Izaguirre, C., Méndez, F. J., Menéndez, M., and Losada, I. J.: Global extreme wave height variability based on satellite data, Geophys. Res. Lett., 38, L10607, https://doi.org/10.1029/2011GL047302, 2011.

Izaguirre, C., Méndez, F. J., Espejo, A., Losada, I. J., and Reguero, B. G.: Extreme wave climate changes in Central-South America, Clim. Change, 119, 277-290, https://doi.org/10.1007/s10584013-0712-9, 2013.

Jiang, H. and Chen, G.: A Global View on the Swell and Wind Sea Climate by the Jason-1 Mission: A Revisit, J. Atmos. Ocean. Tech., 30, 1833-1841, https://doi.org/10.1175/JTECHD-12-00180.1, 2013.

Kalnay, E., Kanamitsu, M., Kistler, R., Collins, W., Deaven, D., Gandin, L., Iredell, M., Saha, S., White, G., Woollen, J., Zhu, Y., Chelliah, M., Ebisuzaki, W., Higgins, W., Janowiak, J., Mo, K. C., Ropelewski, C., Wang, J., Leetmaa, A., Reynolds, R., Jenne, R., and Joseph, D.: The NCEP/NCAR 40-year reanalysis project, B. Am. Meteorol. Soc., 77, 437-470, 1996.

Kumar, V. S. and Naseef, T. M.: Performance of ERA-interim wave data in the nearshore waters around India, J. Atmos. Ocean. Tech., 32, 1257-1269, https://doi.org/10.1175/JTECHD-14-00153.1, 2015.

Melnichenko, O., Hacker, P., Maximenko, N., Lagerloef, G., and Potemra, J.: Spatial Optimal Interpolation of Aquarius Sea Surface Salinity: Algorithms and Implementation in the North Atlantic, J. Atmos. Ocean. Tech., 31, 1583-1600, 2014.

Mori, N., Iwashima, R., Yasuda, T., Mase, H., Tracey, T., and Oku, Y.: Impact of global climate change on wave climate, Coast. Dynam., 135, 36-66, 2009.

Mori, N., Yasuda, T., Mase, H., Tom, T., and Oku, Y.: Projection of Extreme Wave Climate Change under Global Warming, Hydrol. Res. Lett., 4, 15-19, https://doi.org/10.3178/HRL.4.15, 2010.

Murray, R. J. and Simmonds, I.: A numerical scheme for tracking cyclone centers from digital data, Part II: Application to January and July general circulation model simulations, Aust. Meteorol. Mag., 39, 167-180, 1991.

Palutikof, J. P., Brabson, B. B., Lister, D. H., and Adcock, S. T.: A review of methods to calculate extreme wind speeds, Meteorol. Appl., 6, 119-132, 1999.

Panchang, V., Zhao, L., and Demirbilek, Z.: Estimation of extreme wave heights using GEOSAT measurements, Ocean Eng., 26, 205-225, 1999.

Pankratov, K. K.: A comprehensive Matlab Toolbox, http:// mooring.ucsd.edu/index.html, (last access: June 2016), 1995.
Queffeulou, P.: Long-Term Validation of Wave Height Measurements from Altimeters, Mar. Geodesy, 27, 495-510, https://doi.org/10.1080/01490410490883478, 2004.

Queffeulou, P.: Merged altimeter wave height data base, An update, in: ESA Living Planet Symposium 2013, Vol. ESA SP-722, Edinburgh, 2013.

Queffeulou, P. and Croizé-fillon, D.: Global altimeter SWH data set - May 2010, Tech. Rep., Laboratoire d'Océanographie Spatiale IFREMER, 2010.

Queffeulou, P. and Croizé-Fillon, D.: Global altimeter SWH data set - February 2017, Tech. Rep. 11.4, Laboratoire d'Océanographie Spatiale IFREMER, 2017.

Rocha, R. P., Sugahara, S., and Silveira, R. B.: Sea Waves Generated by Extratropical Cyclones in the South Atlantic Ocean : Hindcast and Validation against Altimeter Data, Weather Forecast., 19, 398-410, 2004.

Samayam, S., Laface, V., Annamalaisamy, S. S., Arena, F., Vallam, S., and Gavrilovich, P. V.: Assessment of reliability of extreme wave height prediction models, Nat. Hazards Earth Syst. Sci., 17, 409-421, https://doi.org/10.5194/nhess-17-409-2017, 2017.

Shanas, P., Sanil Kumar, V., and Hithin, N.: Comparison of gridded multi-mission and along-track mono-mission satellite altimetry wave heights with in situ near-shore buoy data, Ocean Eng., 83, 24-35, https://doi.org/10.1016/j.oceaneng.2014.03.014, 2014.

Shanas, P. R. and Sanil Kumar, V.: Comparison of ERA-Interim waves with buoy data in the eastern Arabian Sea during high waves, Ind. J. Mar. Sci., 43, 1343-1346, 2014.

Tournadre, J. and Ezraty, R.: Local Climatology of Wind and Sea State by Means of using from measurements, J. Geophys. Res.-Ocean, 95, 18255-18268, https://doi.org/10.1029/JC095iC10p18255, 1990.

Vinoth, J. and Young, I. R.: Global Estimates of Extreme Wind Speed and Wave Height, J. Climate, 24, 1647-1665, https://doi.org/10.1175/2010JCLI3680.1, 2011.

Wilkin, J. L., Bowen, M. M., and Emery, W. J.: Mapping mesoscale currents by optimal interpolation of satellite radiometer and altimeter data, Ocean Dynam., 52, 95-103, https://doi.org/10.1007/s10236-001-0011-2, 2002.

Wimmer, W., Challenor, P., and Retzler, C.: Extreme wave heights in the North Atlantic from Altimeter Data, Renew. Energ., 31, 241-248, https://doi.org/10.1016/j.renene.2005.08.019, 2006.

Woolf, D. K., Challenor, P. G., and Cotton, P. D.: Variability and predictability of the North Atlantic wave climate, J. Geophys. Res., 107, 3145, https://doi.org/10.1029/2001JC001124, 2002.

Young, I.: An intercomparison of GEOSAT, TOPEX and ERS1 measurements of wind speed and wave height, Ocean Eng., 26 , 67-81, https://doi.org/10.1016/S0029-8018(97)10016-6, 1999.

Young, I. R., Zieger, S., and Babanin, A. V.: Global trends in wind speed and wave height, Science, 332, 451-455, https://doi.org/10.1126/science.1197219, 2011.

Young, I. R., Vinoth, J., Zieger, S., and Babanin, A. V.: Investigation of trends in extreme value wave height and wind speed, J. Geophys. Res., 117, C00J06, https://doi.org/10.1029/2011JC007753, 2012.

Zieger, S., Vinoth, J., and Young, I. R.: Joint Calibration of Multiplatform Altimeter Measurements of Wind Speed and Wave Height over the Past 20 Years, J. Atmos. Ocean. Tech., 26, 25492564, https://doi.org/10.1175/2009JTECHA1303.1, 2009. 